\title{
Physical and Physiological Comparison Between Indian Female College Basketball Players and Sedentary Students
}

\author{
Kaushik Halder ${ }^{1}$, Anjana Pathak ${ }^{1}$, O. S. Tomer ${ }^{1}$, Abhirup Chatterjee ${ }^{2}$, Mantu Saha ${ }^{1, *}$ \\ ${ }^{1}$ Exercise Physiology and Yoga Division, Defence Institute of Physiology and Allied Sciences (DIPAS), Defence Research and Development \\ Organization (DRDO), Min. Of Defence, Lucknow Road, Timarpur, Delhi, India \\ ${ }^{2}$ Centre for Advanced Research and Training in Yoga (CARTY), Defence Institute of Physiology and Allied Sciences (DIPAS), Defence \\ Research and Development Organization (DRDO), Min. of Defence, Lucknow Road, Timarpur, Delhi, India
}

\section{Email address:}

halderkaushik@gmail.com (K. Halder), anjanapathak6@gmail.com (A. Pathak), omveer_tomar@yahoo.com (O. S. Tomer), abhirup2k4@gmail.com (A. Chatterjee),msaha1234@yhaoo.com (M. Saha)

\section{To cite this article:}

Kaushik Halder, Anjana Pathak, O. S. Tomer, Abhirup Chatterjee, Mantu Saha. Physical and Physiological Comparison Between Indian Female College Basketball Players and Sedentary Students. Advances in Applied Physiology. Vol. 1, No. 2, 2016, pp. 18-23. doi: 10.11648/j.aap.20160102.11

\begin{abstract}
The study aimed to assess and compare the physical and physiological performances of Indian female college basketball players (BB) with sedentary females (SS) of same age group. Randomly selected 20 female college students, 10 each in 2 groups, BB $(19.0 \pm 0.8)$ and SS $(19.7 \pm 1.3)$ respectively, volunteered for this study. Standing height, body weight, resting blood pressure, resting and maximum heart rate (RHR and MHR respectively), resting oxygen consumption $\left(\mathrm{VO}_{2 \text { rest }}\right)$, maximal aerobic capacity $\left(\mathrm{VO}_{2 \max }\right)$, anaerobic power, hand grip strength (HGS) and back leg strength (BLS) were recorded. Body surface area (BSA), body mass index (BMI), maximum oxygen pulse $\left(\mathrm{O}_{2} \mathrm{P}_{\max }\right)$, fatigue percentage and relative peak power output (RPP) were calculated. Significant difference was observed between BB and SS in body weight $(\mathrm{P}<0.001)$, BSA $(\mathrm{P}<0.01)$, BMI $(\mathrm{P}<0.001)$, HGS (left; $\mathrm{P}<0.05$ and right; $\mathrm{P}<0.01)$ and $\mathrm{BLS}(\mathrm{P}<0.01)$. No significant difference was observed in height and blood pressure among the players and sedentary females, while, significantly lower RHR $(\mathrm{P}<0.01)$, higher MHR $(\mathrm{P}<0.01), \mathrm{VO}_{2 \max }(\mathrm{P}<0.001), \mathrm{O}_{2} \mathrm{P}_{\max }(\mathrm{P}<0.01)$ were noted in sportswomen compared to sedentary females. Peak anaerobic power, average anaerobic power (both $\mathrm{P}<0.01)$ and RPP $(\mathrm{P}<0.001)$ of sportswomen was also significantly higher than the sedentary group. The study revealed that female college basketball players were physiologically potent than sedentary students of similar age group. It is once again substantiated the fact that involvement in sports or games like basketball, renders a person with better physiological health and physical fitness as compared to sedentary individuals.
\end{abstract}

Keywords: Basketball, Aerobic Capacity, Anaerobic Power, Muscle Strength, Physical Fitness

\section{Introduction}

Basketball game necessitates high level of physical fitness which includes flexibility, neuromuscular efficiency, muscular strength and speed of each individual player [1-4]. The integrated relationship among body composition, aerobic fitness, anaerobic power and playing position of basketball players renders a team the competitive success [5]. To perform commonly used essential techniques like footwork, shooting, passing and catching, dribbling, rebounding, moving with and without the ball and defending, players of this ball game utilize energy from both aerobic and anaerobic sources of energy production during an event [5-7]. Superior body height, litheness, agility, muscular strength and eye-hand coordination are also required to prevail in a contest [8-11].

Remarkable changes have been perceived in basketball game as a result of modification of rules [9] with special reference to physical and tactical demands; which has drawn considerable attention towards identification of physiological requirements for modern basketball.

Despite considerable scientific information on physical and physiological performance of basketball players [1014], literature is still scanty with reference to Indian female basketball players especially in the junior level. So far, there is no comparative report on physical fitness of Indian college level female basketball players with sedentary healthy female students of same age group. Our study was therefore aimed to compare the physical and physiological health and fitness of female basketball players and 
sedentary healthy female students, thus evaluating the potential benefit of sports, like basketball.

\section{Materials and Methods}

\subsection{Subject}

Twenty healthy young female student volunteers, drawn randomly from a College at Delhi, India, participated in the study. They were divided into two equal groups - (i) Basketball players $(\mathrm{BB})\left[\mathrm{n}_{1}=10\right.$, age $18.9 \pm 1.0$ (Mean \pm $\mathrm{SD})$ ], with a training experience of $2-6$ years and (ii) Sedentary Students (SS) $\left[\mathrm{n}_{2}=10\right.$, age $20.3 \pm 1.4$ (Mean \pm $\mathrm{SD})$, healthy female college students with no previous exposure to any kind of sports or exercise. All of them were explained the purpose of the study and their role therein. Individual written informed consent was obtained from them as per Declaration of Helsinki [15]. A representative prototype for physical training schedule of $\mathrm{BB}$ is shown in Table 1.

The volunteers were requested to refrain from eating, drinking or doing any kind of strenuous physical work at least for 2 hours before the onset of experiments. They were also allowed to take a rest for a minimum period of 30 minutes so that their heart rate may come down to a steady state.

\subsection{Parameters}

\subsubsection{Anthropometric Measurements}

Anthropometric measurements were obtained from the volunteers with minimal clothing and barefoot. The standing body height was measured without shoes to the nearest 0.1 $\mathrm{cm}$ from sole of the feet to the vertex in erect body position, with the help of a stadiometer. Body weight (in $\mathrm{kg}$ ) was measured with empty bladder and stomach using standard digital weighing machine (ID150H, Delmar, India).

Body mass index (BMI) was calculated as the ratio of weight to height squared. Body surface area (BSA) was calculated by using Du Bois formula [16].

\subsubsection{Resting Parameters}

The resting heart rate in bpm and blood pressure (systolic and diastolic) in $\mathrm{mmHg}$ were recorded by using Delmar Pressurometer (P6, Delmar, USA).

\subsubsection{Aerobic Work Capacity}

Resting $\left(\mathrm{VO}_{2 \text { rest }}\right.$ in L.min- $\left.{ }^{1}\right)$ and maximal oxygen consumption $\left(\mathrm{VO}_{2 \max }\right.$ in $\left.\mathrm{ml} . \mathrm{kg}_{-}{ }^{1} \mathrm{~min}^{-}{ }^{1}\right)$ were measured by using computerized equipment set-up (K4b $\mathrm{b}^{2}$, COSMED, Italy). Exercise was performed on a bicycle ergometer (Monark-Ergomedic 828E, Monark Exercise AB, Sweden). Cycling protocols began with warm-up without any workload followed by regular graded incremental work-load of 25 watts in every 2 minutes keeping cycling speed at $50 \mathrm{rpm}$. Exercise continues with the said protocol until a plateau of $\mathrm{VO}_{2}$ was attained or the subject was unable to continue paddling at the defined pace. The oxygen consumption recorded at the point of maximum heart rate denotes the
$\mathrm{VO}_{2 \max }$. Recovery heart rate $\left(\mathrm{HR}_{\text {reco }}\right)$ and oxygen consumption $\left(\mathrm{VO}_{2 \text { reco }}\right.$ in L.min- $\left.{ }^{1}\right)$ were noted after five minutes of maximum oxygen consumption. Heart rate was monitored and recorded continuously with a heart rate belt (Polar Electro OY, T34, Polar), telemetrically connected to $\mathrm{K} 4 \mathrm{~b}^{2}$ system. Maximum oxygen pulse $\left(\mathrm{O}_{2} \mathrm{P}_{\max }\right)$ was calculated by dividing maximum oxygen uptake with maximum heart rate, both obtained during the attainment of $\mathrm{VO}_{2 \max }$.

\subsubsection{Anaerobic Work Capacity}

Anaerobic power of leg was determined by using Wingate Anaerobic Power test protocol [17] on a mechanically braked bicycle ergometer (Monark Ergomedic 894E, Monark Exercise AB, Sweden). After familiarization with the bicycle and the technique used, warming up exercise with no resistance was performed by the volunteers. After warm up, the volunteers began pedaling by leg as fast as possible without any resistance. After achieving maximum rpm, a fixed resistance, as per software predicted weight, was applied to the flywheel and the participants continued to pedal "all out" for 30 seconds. A computerized software controlled the entire test. Anaerobic work capacity was obtained as peak power (W.kg- $\left.{ }^{1}\right)$, average power (W.kg- ${ }^{1}$ ) and minimum power (W.kg-1). Fatigue percentage (\%) and relative peak power output (W.kg- ${ }^{1}$ ) were calculated by using standard formula.

\subsection{Muscular Strength}

Right and left hand grip strength in $\mathrm{kg}$ was measured by Hand Grip Dynamometer (Grip - D, T.K.K.5401, Takei, Tokyo, Japan), after adjustment to individual grip size. Back leg strength, in $\mathrm{kg}$, of the volunteers was measured by using a Back Leg Dynamometer (Back - D, T.K.K.5402, Takei, Tokyo, Japan). The participants were asked to stand on the dynamometer foot-stand and hold the bar with alternate grip. They were asked to pull the bar straight as much as possible without bending the knees and lifting heels. For both the experiments each volunteer performed 3 trials with a rest of 30 seconds between each trial. The highest score of the trials was recorded as the corresponding hand grip and back leg strength.

\subsection{Statistical Analysis}

Statistical analysis was done using SPSS for Windows release 13.0 and values were expressed as Mean \pm SD. Twotailed Student's $t$-test for small $(\mathrm{n}<30)$ paired samples was used to test the significance of difference between the means. The computed $t$ was then compared with the critical $t$ scores for different levels of significance to accept or reject Ho. Statistical significance was set at $\mathrm{P} \leq 0.053$.

\section{Results}

Physical and physiological characteristics of the two groups, BB and SS, were presented in Table 2. Body weight of collegiate $\mathrm{BB}$ was significantly lower $(\mathrm{P}<0.001)$ than SS. 
BSA of BB was lower than SS and the difference was statistically significant $(\mathrm{P}<0.01)$. BMI was significantly lower $(\mathrm{P}<0.001)$ in $\mathrm{BB}$ than their sedentary counterparts. Hand grip strength (both left and right) of $\mathrm{BB}$ was significantly higher $((\mathrm{P}<0.05$ and $\mathrm{P}<0.01$ respectively) than SS. Back leg strength of female BB was higher than SS and the difference was statistically significant $(\mathrm{P}<0.01)$. Standing height and resting blood pressure (both systolic and diastolic) did not register any significant difference between two study groups.

Table 3 shows the aerobic performance of college $\mathrm{BB}$ and SS. Resting heart rate of $\mathrm{BB}$ was significantly lower $(\mathrm{P}<0.01)$ than $\mathrm{SS}$; while difference in $\mathrm{VO}_{2 \text { rest }}$ was not significant. Maximum heart rate (MHR) and $\mathrm{VO}_{2 \max }$ of $\mathrm{BB}$ was significantly higher $(\mathrm{P}<0.01$ and $\mathrm{P}<0.001$ respectively $)$ than
SS. $\mathrm{O}_{2} \mathrm{P}_{\max }$ was significantly higher $(\mathrm{P}<0.01)$ in $\mathrm{BB}$ compared to their sedentary counterparts. $\mathrm{HR}_{\text {reco }}$ and $\mathrm{VO}_{2 \text { reco }}$ of the participants recorded for 5 minutes after achieving $\mathrm{VO}_{2 \max }$ were presented in Table 2 and also in Figure 1 . $\mathrm{HR}_{\text {reco }}$ and $\mathrm{VO}_{2 \text { reco }}$ at $5^{\text {th }}$ minutes of recovery of $\mathrm{BB}$ was significantly lower (both $\mathrm{P}<0.001$ ) than SS.

Anaerobic profile of the participants showed significantly higher peak power and average power (both $\mathrm{P}<0.01$ ) of athletes than non-athletes (Table 4). Minimum power registered a non-significant trend of higher values in sportswomen compared to sedentary students. Fatigue percentage was lower in BB than SS, but the difference was statistically not significant. Relative peak power output of female $\mathrm{BB}$ was higher than $\mathrm{SS}$ and the difference was statistically significant $(\mathrm{P}<0.001)$.

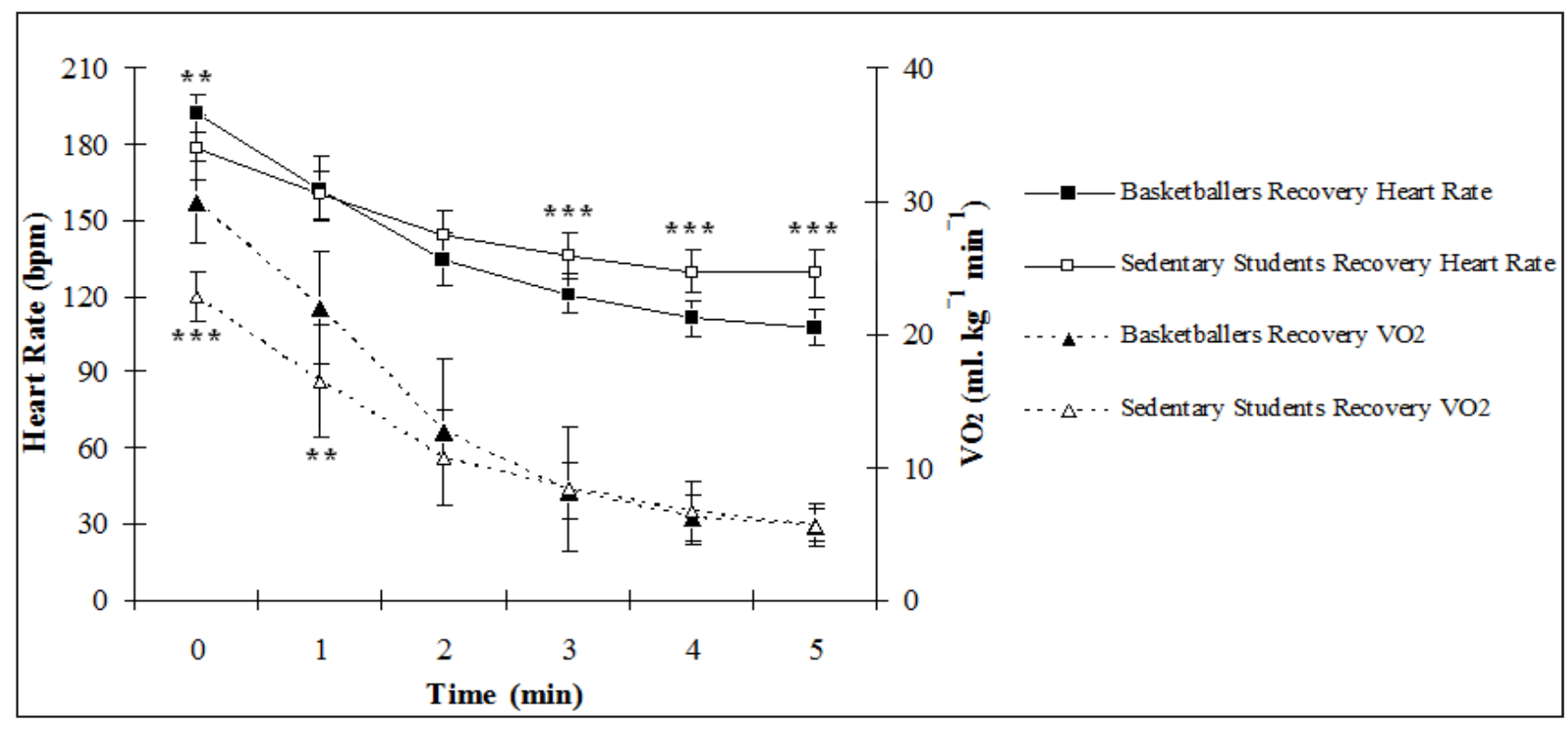

$* \mathrm{P}<0.05 ; * * \mathrm{P}<0.01 ; * * * \mathrm{P}<0.001$.

Fig. 1. Recovery heart rate and $\mathrm{VO}_{2}$ of $\mathrm{BB}$ and SS recorded for 5 minutes after achieving $\mathrm{VO}_{2 \max }$

Table 1. Experiential training schedule for female basketball players.

\begin{tabular}{|c|c|c|c|}
\hline $\begin{array}{l}\text { S/L } \\
\text { No. }\end{array}$ & Activity & $\begin{array}{l}\text { M / Min } \\
\text { /Round }\end{array}$ & $\begin{array}{l}\text { Conditioning } \\
\text { Aspect }\end{array}$ \\
\hline 1. & Basketball Agility Drills & 06 & Speed \& agility \\
\hline 2. & Sprints & 14 & Anaerobic \\
\hline 3. & Shuttle running & 10 & Aerobic \\
\hline 4. & Ball running (With dribbling) & 12 & Anaerobic \\
\hline 5. & $\begin{array}{l}\text { Two men pass(With running \& } \\
\text { lap shot) }\end{array}$ & 15 & Flexibility \\
\hline 6. & Sit-ups & 3 & Strength \& power \\
\hline 7. & Push-ups & 3 & Strength \& power \\
\hline 8. & Medicine Ball (4 kg) & 2 & $\begin{array}{l}\text { Core strength \& } \\
\text { reaction time }\end{array}$ \\
\hline 9. & Dumbbells & $2 \times 6$ & $\begin{array}{l}\text { Muscular strength } \\
\& \text { endurance }\end{array}$ \\
\hline 10. & Regular game practice & 59 & Overall practice \\
\hline 11. & $\begin{array}{l}\text { Fundamental skill practice } \\
\text { (Defending shuffles, } \\
\text { Dribbling, Shooting, Passing) } \\
\end{array}$ & 30 & Performance \\
\hline
\end{tabular}

Table 2. Principle anthropometric and physiological characteristics of the participants.

\begin{tabular}{lll}
\hline \multirow{2}{*}{ Parameters } & Basket ballers & Sedentary Students \\
\cline { 2 - 3 } & $\left(\mathbf{n}_{\mathbf{1}}=\mathbf{1 0}\right)$ & $\left.\mathbf{( n}_{\mathbf{2}}=\mathbf{1 0}\right)$ \\
\hline Age $($ years $)$ & $19.0 \pm 0.8$ & $19.7 \pm 1.3$ \\
Height $(\mathrm{cm})$ & $159.5 \pm 3.3$ & $157.4 \pm 4.4$ \\
Body weight $(\mathrm{kg})$ & $49.7 \pm 3.5$ & $57.0 \pm 4.4^{* * *}$ \\
BSA $\left(\mathrm{m}^{2}\right)$ & $1.4 \pm 0.1$ & $1.5 \pm 0.1^{* *}$ \\
BMI $\left(\mathrm{kg} / \mathrm{m}^{2}\right)$ & $19.7 \pm 1.5$ & $23.0 \pm 1.7^{* * *}$ \\
SBP $(\mathrm{mmHg})$ & $117.4 \pm 5.6$ & $121.5 \pm 3.2$ \\
DBP $(\mathrm{mmHg})$ & $71.2 \pm 2.9$ & $73.7 \pm 4.0$ \\
LGS $(\mathrm{kg})$ & $24.7 \pm 2.0$ & $22.9 \pm 1.7^{*}$ \\
RGS $(\mathrm{kg})$ & $26.6 \pm 2.3$ & $23.5 \pm 2.1^{* *}$ \\
BLS $(\mathrm{kg})$ & $70.8 \pm 7.0$ & $58.9 \pm 8.3^{* *}$ \\
\hline
\end{tabular}

Values are expressed as Mean $\pm \mathrm{SD}$. ${ }^{*} \mathrm{P}<0.05 ; * * \mathrm{P}<0.01 ; * * * \mathrm{P}<0.001$. $\mathrm{BSA}=$ Body surface area; $\mathrm{BMI}=$ Body mass index; $\mathrm{SBP}=$ Systolic blood pressure; $\mathrm{DBP}=$ Diastolic blood pressure; $\mathrm{MBP}=$ Mean blood pressure; RGS $=$ Right hand grip strength; LGS $=$ Left hand grip strength; BLS = Back leg strength. 
Table 3. Aerobic profile of the participants.

\begin{tabular}{|c|c|c|}
\hline \multirow{2}{*}{ Parameters } & Basket ballers & Sedentary Students \\
\hline & $\left(n_{1}=10\right)$ & $\left(\mathrm{n}_{2}=10\right)$ \\
\hline \multicolumn{3}{|l|}{ Resting (Pre exercise) } \\
\hline HR (beats.min ${ }^{-1}$ ) & $75.4 \pm 6.4$ & $84.6 \pm 5.3 * *$ \\
\hline $\mathrm{VO}_{2}\left(\mathrm{~L} \cdot \mathrm{min}^{-1}\right)$ & $0.2 \pm 0.04$ & $0.2 \pm 0.03$ \\
\hline \multicolumn{3}{|l|}{ Exercise } \\
\hline HR (beats. $\min ^{-1}$ ) & $192.3 \pm 7.3$ & $178.6 \pm 12.3 * *$ \\
\hline $\mathrm{VO}_{2}\left(\mathrm{~L} \cdot \mathrm{min}^{-1}\right)$ & $1.5 \pm 0.2$ & $1.2 \pm 0.1 * *$ \\
\hline $\mathrm{VO}_{2} \max \left(\mathrm{ml} \cdot \mathrm{kg}^{-1} \cdot \mathrm{min}^{-1}\right)$ & $30.0 \pm 3.1$ & $22.8 \pm 1.9 * * *$ \\
\hline $\mathrm{O}_{2} \mathrm{P}_{\max }\left(\mathrm{ml}\right.$. beat $\left.^{-1}\right)$ & $8.0 \pm 0.8$ & $6.6 \pm 0.9 * *$ \\
\hline \multicolumn{3}{|l|}{ Recovery (after $5 \mathrm{~min}$ ) } \\
\hline HR (beats.min ${ }^{-1}$ ) & $107.7 \pm 7.1$ & $129.2 \pm 9.4 * * *$ \\
\hline $\mathrm{VO}_{2}\left(\mathrm{~L} \cdot \mathrm{min}^{-1}\right)$ & $0.2 \pm 0.05$ & $0.3 \pm 0.02 * * *$ \\
\hline
\end{tabular}

Values are expressed as Mean $\pm \mathrm{SD}$. $* \mathrm{P}<0.05 ; * * \mathrm{P}<0.01 ; * * * \mathrm{P}<0.001$. $\mathrm{HR}=$ Heart rate; $\mathrm{VO}_{2} \max =$ maximum oxygen consumption; $\mathrm{O}_{2} \mathrm{P}_{\max }=$ Maximum oxygen pulse

Table 4. Anaerobic profile of the participants.

\begin{tabular}{lll}
\hline \multirow{2}{*}{ Parameters } & Basket ballers & Sedentary Students \\
\cline { 2 - 3 } & $\left(\mathbf{n}_{\mathbf{1}}=\mathbf{1 0}\right)$ & $\left.\mathbf{n}_{\mathbf{2}}=\mathbf{1 0}\right)$ \\
\hline Peak Power $\left(\mathrm{W} \cdot \mathrm{kg}^{-1}\right)$ & $9.0 \pm 1.2$ & $7.5 \pm 1.2 * *$ \\
Average Power $\left(\mathrm{W}_{\mathrm{kg}} \mathrm{kg}^{-1}\right)$ & $4.7 \pm 0.4$ & $4.2 \pm 0.4 * *$ \\
Minimum Power $\left(\mathrm{W}_{\mathrm{kg}} \mathrm{kg}^{-1}\right)$ & $3.2 \pm 1.8$ & $2.5 \pm 1.4$ \\
Fatigue \% $(\%)$ & $62.7 \pm 24.2$ & $65.8 \pm 19.7$ \\
RPP $\left(\mathrm{W} \cdot \mathrm{kg}^{-1}\right)$ & $0.2 \pm 0.03$ & $0.1 \pm 0.03 * * *$ \\
\hline
\end{tabular}

Values are expressed as Mean $\pm \mathrm{SD}$. ${ }^{* *} \mathrm{P}<0.01 ; * * * \mathrm{P}<0.001$.

$\mathrm{RPP}=$ Relative peak power output.

\section{Discussion}

The present study approached to compare the physical fitness and physiological health of Indian college female basketball players with sedentary Indian college women of same age group. The novelty of the study is that it illustrated a thorough systematic evaluation of Indian college women both sportswomen and sedentary, which exists rarely in this context.

Standing height is one of the cardinal physical attribute for basketball players since this game requires frequent handling of the ball above the head [18]. In the present study, the non significant difference in standing body height between BB and SS might likely to be due to mixed ethnicities of the volunteers. In basketball, for performing different playing techniques a definite sport-specific body weight of all the players is very much required $[4,19]$. BMI of both the study groups were found to be within the range of 'normal' as per classification of WHO [20]. A significantly lower body weight, thereby BMI, and BSA in BB than SS, as observed in the present study, might be due to their sports-specific involvement (in basketball). Non-significant difference in blood pressure (systolic, diastolic and mean) could be due to similar diet pattern (vegetarian) and more-or-less uniform daily activity schedule of the volunteers.
Time motion analysis revealed that players spend $34.1 \%$ of their play time in running and jumping, $56.8 \%$ in walking and $9.0 \%$ in standing on an average [21]. Movement pattern in basketball is intermittent in nature, consisting of repeated bouts of brief maximal or near maximal work and relatively short moderate or low intensity recovery period [4]. Considering activity pattern in modern basketball matches, it was found that women basketball players reached up to $94.6 \%$ and $90.8 \%$ of their MHR value during International and National matches respectively [22]. So, a significantly lower resting heart rate and a higher maximal heart rate of basketball players than sedentary students as observed in our study is certainly relevant. These results also indicate that aerobic training results in the enhanced vagal activities in $\mathrm{BB}$, which may contribute in part to the resting bradycardia in BB [23]. A significant difference in recovery heart rate (Fig.1) after maximal exercise between BB and SS could also be due to an improved synchronized interplay of parasympathetic reactivation and sympathetic withdrawal in $\mathrm{BB}$ [24].

A high level of aerobic fitness is essential in competitive basketball event. Maximal aerobic capacity, being a direct determinant of better basketball performance, facilitates the selection of players and helps to discriminate between higher and lower skilled players [25]. $\mathrm{VO}_{2 \max }$ is an important determinant of the ability to perform high intensity intermittent exercise and faster recovery between exercise bouts. In our study, mean $\mathrm{VO}_{2 \max }$ of female basketball players was $31.6 \%$ higher than their sedentary counterparts. This higher $\mathrm{VO}_{2 \max }$ of $\mathrm{BB}$ might be due to the specific physical training protocol (related to basketball). The correlation between aerobic capacity and activity level of basketball players also suggests the potential advantage of proper aerobic training in this game [21]. Higher $\mathrm{VO}_{2 \max }$ of BB than SS, could be due to their training which has been shown to contribute for maximal increase in cardiac output, stroke volume and arterio-venous oxygen difference [26]. The $\mathrm{O}_{2}$ pulse is an important parameter of cardio-vascular efficiency and it is closely related to health and cardiopulmonary function [27]. High $\mathrm{O}_{2} \mathrm{P}_{\max }$ represents a high stroke volume and cardiac output with an increased oxygen delivery to the working muscles by each heart beat during maximal exercise thus implicating an improved performance of the cardiovascular system of the basketball player. Rapid fall of heart rate after a bout of high-intensity exercise, as observed in female basketball players in our study, could be an indicator of efficient functioning of neurohormonal mechanism that had been developed due to proper aerobic training [28].

Basketball is a multiple-sprint game which requires strong agility, repetitive jump-\&-land and sudden change in direction [29]. For performing different high intensity activities in this ball game, a considerable involvement of anaerobic glycolysis as an energy source has been indicated [30]. So for a competitive success in this ball game, anaerobic power is also required along with aerobic power. Sometimes basketball appears to depend more on anaerobic power than aerobic capacity, as anaerobic requirements are 
preponderant and repetitive during a match [31-32]; thus emphasizing the contribution of anaerobic power in this game [33]. In the present study anaerobic power of basketball players was significantly higher than sedentary students. The BB players might attain a higher extent of anaerobic power than sedentary individuals perhaps through their training to perform short duration; high-intensity burst activities, as this high power output is highly required during the game.

Apart from length and perimeter of hand, grip strength is another important attribute for accuracy of throwing and tackling the ball in ball games [34]. Grip strength (both left and right) of $\mathrm{BB}$ in the present study was significantly higher (7.9\% and $13.2 \%$ respectively) than SS. A strong grip is important in basketball for two principal reasons - first is the ability to hold the ball with single hand using fingertips and palm; and the second is the ability to keep possession of the ball if opponents attempts to swat the ball. Literature supports that, in young college athletes, isometric grip strength is one of the key determinant of dominant radial bone mineral density [35]. Earlier researches also revealed significantly higher grip strength in athletes compared to non-athletes [36]. Back leg strength is also cardinal in basketball for various skilled executions while competing in the event [37]. In the present study back leg strength of BB was $20.2 \%$ higher than SS.

However the findings suggest that, the BB was more efficient than SS in terms of significantly higher aerobic capacity and anaerobic power, along with higher muscular strength, thus reflecting a better level of physical fitness and physiological health. It could be worthy to comment that, this improvement might have been achieved through physical training.

\section{Conclusion}

As a game, basketball demands optimum aerobic and anaerobic fitness along with muscle strength and power and other physical capacities. The present study summarized the fact that Indian female college basketball players were physiologically more efficient than healthy sedentary female students of same age group. Furthermore, our findings necessitate the prime requirement of extensive in-depth research on Indian women basketball players at all levels so as to provide a critical insight into physical training and practice of the players thus resulting in better performance with reduced risk of injury.

\section{Acknowledgement}

Authors are grateful to Director, Defence Institute of Physiology and Allied Sciences (DIPAS), Delhi, for the guidance and support for carrying out the work in DIPAS. Above all, the unstinted cooperation and support of Ms. Mansi Chopra, M.Sc. student of Lady Irwin College, Delhi and the student volunteers are cordially acknowledged.

\section{References}

[1] Smith HK, Thomas SG. Physiological characteristics of elite female basketball players. Can J Sport Sci, 1991; 16(4): 289295.

[2] Kohmura Y, Aoki K, Yoshigi H, Sakuraba K, Yanagiya T. Development of a baseball-specific battery of tests and a testing protocol for college baseball players. J Strength Cond Res, 2008 Jul; 22(4): 1051-8.

[3] MacLaren D. Court games: volleyball and basketball. In: Reilly T, Secher N, Snell P, Williams C, editors. Physiology of Sports, Spoon Press, Milton Park, Abingdon, Oxon; 2002, pp 427-464.

[4] Hoffman JR. Physiology of basketball. In: McKeag DB, editor Handbook of Sports Medicine and Science, Blackwell Science Inc, Malden; 2003, pp 12-24.

[5] Ostojic SM, Mazic S, Dikic N. Profiling in basketball: physical and physiological characteristics of elite players. $J$ Strength Cond Res, 2006; Nov; 20(4): 740-744.

[6] Narazaki K, Berg K, Stergiou N, Chen B. Physiological demands of competitive basketball. Scand J Med Sci Sports, 2009; Jun; 19(3): 425-432.

[7] Abdelkrim NB, Fazaa SE, Ati JE. Time-motion analysis and physiological data of elite under- 19-year-old basketball players during competition. Br J Sports Med, 2007; 41: 69-75.

[8] Tsunawake N, Tahara Y, Moji K, Muraki S, Yukawa Minowa K, Koichi Y. Body Composition and Physical Fitness of Female Volleyball and Basketball Players of the Japan Interhigh School Championship Teams. J Physiol Anthropol Appl Human Sci, 2003; 22 (4): 195-201.

[9] Official basketball rule for men and women. Federation Internationale De Basketball (FIBA), Central board of FIBA, Munich, Germany, 2000.

[10] Sodhi HS. Kinanthropometry and performance of top ranking Indian basketball players. Brit J Sports Med, 1980; 14 (9): 139-144.

[11] De AK, Bhattacharya AK, Panda BK, Das Gupta PK. Respiratory performance and grip strength tests on the basketball players of inter-university competition. Indian $J$ Physiol Pharmacol. 1980; 24(4): 305-9.

[12] Muthiah CM, Sodhi HS. The effect of training on some morphological parameters of top-ranking Indian basketball players. J Sports Med Phys Fitness. 1980; 20(4): 405-12.

[13] Sodhi HS. A study of morphology and body composition of Indian basketball players. J Sports Med Phys Fitness. 1980; 20(4): 413-22.

[14] Ghosh AK, Paliwal R, Sam MJ, Ahuja A. Effect of 4 weeks detraining on aerobic \& anaerobic capacity of basketball players \& their restoration. Ind J Med Res, 1987; 86: 522-527.

[15] Rid A, Schmidt H. The 2008 Declaration of Helsinki — First among Equals in Research Ethics? The Journal of Law, Medicine \& Ethics, 2010; 38 (1): 143-148.

[16] DuBois D, DuBois EF. A formula to estimate the approximate surface area if height and weight be known. Arch Intern Medicine. 1916; 17: 863-871. 
[17] Bar-Or O. The Wingate anaerobic test. An update on methodology, reliability and validity. Sports Med, 1987; 4: 381-391.

[18] Tsunawake N, Tahara Y, Moji K, Muraki S, Yukawa Minowa K, Koichi Y. Body Composition and Physical Fitness of Female Volleyball and Basketball Players of the Japan Interhigh School Championship Teams. J Physiol Anthropol Appl Human Sci, 2003; 22 (4): 195-201.

[19] Ostojic SM, Mazic S, Dikic N. Profiling in basketball: physical and physiological characteristics of elite players. $J$ Strength Cond Res, 2006; 20(4): 740-744.

[20] Obesity: preventing and managing the global epidemic. Report of a WHO Consultation. WHO Technical Report Series 894. Geneva: World Health Organization, 2000.

[21] Narazaki K, Berg K, Stergiou N, Chen B. Physiological demands of competitive basketball. Scand J Med Sci Sports, 2009; 19(3): 425-432.

[22] Rodríguez-Alonso M, Fernández-García B, Pérez-Landaluce J, Terrados N. Blood lactate and heart rate during national and international women's basketball. J Sports Med Phys Fitness. 2003; 43(4): 432-6.

[23] Smith ML, Hudson DL, Graitzer HM, Raven PB. Exercise training bradycardia: the role of autonomic balance. Med Sci Sports Exerc. 1989; 21: 40-44.

[24] Borresen J, Lambert MI. Autonomic control of heart rate during and after exercise: measurements and implications for monitoring training status. Sports Med. 2008; 38: 633-646.

[25] Riezebos ML, Paterson DH, Hall CR, Yuhasz MS. Relationship of selected variables to performance in women's basketball. Can J Appl Sport Sci, 1983; 8(1): 34-40.

[26] Cunningham DA, Hill JS. Effect of training on cardiovascular response to exercise in women. $J$ Appl Physiol. 1975; 39(6): 891-895.

[27] Wasserman K, Hansen J, Sue DY, Casaburi R, Whipp B J. Measurements during integrative cardiopulmonary exercise testing. In: Wasserman K, Hansen J, Sue DY, Casaburi R, Whipp B J.; editors. Principles of exercise testing and interpretation (3 rd ed). Philadelphia: Lippincott, Williams \& Wilkins, 1999, pp - 91-92.
[28] Borresen J, Lambert MI. Autonomic control of heart rate during and after exercise: measurements and implications for monitoring training status. Sports Med, 2008; 38(8): 633-46.

[29] Sigmon C. Fifty-two week basketball training. In: Sigmon C, editor. Program Components, Human Kinetics, 2003; pp 3-16.

[30] McInnes SE, Carlson JS, Jones CJ, McKenna MJ. The physiological load imposed on basketball players during competition. Sports Sci. 1995; 13(5): 387-397.

[31] Hoffman JR, Marsh CM. Physiology of Basketball. In: Garrett WE Jr, Kirkendall DT, editors. Exercise and sport science. Lippencott, Williams \& Wilkins; 2000; pp 733-744.

[32] Hoffman JR, Tennenbaum G, Marsh CM, Kraemer WJ. Relationship between athletic performance tests and playing time in elite college basketball players. J Strength Cond Res, 1996; 10: 67-71.

[33] Delextrat A, Cohen D. Physiological testing of basketball players: toward a standard evaluation of anaerobic fitness. $J$ Strength Cond Res, 2008; 22(4): 1066-1072.

[34] Visnapuu M, Jürimäe T. Handgrip strength and hand dimensions in young handball and basketball players. $J$ Strength Cond Res, 2007; 21(3): 923-929.

[35] Tsuji S, Tsunoda N, Yata H, Katsukawa F, Onishi S, Yamazaki H. Relation between grip strength and radial bone mineral density in young athletes. Arch Phys Med Rehabil, 1995; 76(3): 234-238.

[36] Bhargava AS, Eapen C, Kumar SP. Grip strength measurements at two different wrist extension positions in chronic lateral epicondylitis-comparison of involved vs. uninvolved side in athletes and non athletes: a case-control study. Sports Medicine, Arthroscopy, Rehabilitation, Therapy \& Technology, 2010; 2: 22.

[37] Miller FY, Coffey W. Preparation for success - getting in shape In: Miller FY, Coffey W.; editors. Wining basketball for girls. Chelsea House, New York. $4^{\text {th }}$ edition, 2009; pp 21. 